\title{
Comfortable Room Condition for Working and Resting
}

\author{
Jovina Evangeline Wardana, Ova Candra Dewi, Joice Sandra Sari \\ Department of Architecture, Faculty of Engineering, Universitas Indonesia, Depok, Indonesia
}

Corresponding e-mail: ova.candewi@ui.ac.id

Article info:

Received: 02-03-2021, Revised: 17-04-2021, Accepted: 24-04-2021

\begin{abstract}
This paper aims to determine the comfortable room condition in terms of room organization, lighting and room temperature. Due to the pandemic, many workers are forced to bring their outside home activities back home. Many of them struggle in finding one suitable and comfortable space as they do not have a dedicated space to do the work from home. A bedroom, as one of the potential rooms to maintain the balance between work and rest at home, are observed for space adjustment, especially the organization of space, lighting and room temperature to maintain the comfort. The comfortable room condition needs to support the bedroom as a working and relaxing space. This study consists of literature review about space, lighting and temperature and observation of two study case studies. This study concludes that the room organization, lighting and room temperature affects the user physically and psychologically which results in the comfort of the user. As a worker, to increase comfort level and have good rest balance, the user needs to adjust the variables of lighting, room temperature and room organization to achieve the optimum comfort level.
\end{abstract}

Keywords: Comfort, Lighting, Resting, Room Temperature, Working

\section{Introduction}

The pandemic forces people to limit their routines such as travel restrictions and quarantines to minimize the spread of the virus (Goh, Lu, \& Jou, 2020). Consequently, the time spent by people at their homes increases. The change of the average staying at home duration of every country in the world is increasing and by far the highest change is reaching almost $40 \%$ (OurWorldInData.org, 2020). People's way of life has to adapt to the current situation where people need to work from home and limit their contact with other people (Establishing a New Daily Routine During the COVID-19 Pandemic, 2020). The total human steps worldwide decreased by $12 \%$ in April 2020 by the time the coronavirus spread throughout the world (Garmin, 2020). The decrease of total steps worldwide is influenced by the government's order to stay at home. The president of Indonesia, Mr. Joko Widodo instructed Indonesian citizens to be more aware of the coronavirus's current development by doing work from home (KOMPAS, 2020). The news reported that work from home may encounter problems in terms of the technological infrastructure needed to implement such a concept at home. (KOMPAS, 2020). Many people are working from home and not all of them have a dedicated home office that is equipped with the same tools such as those at work (Scripps Health, 2020). It may introduce a few challenges to the workers. The first one is the boundaries between the time to work and rest (Van. Horn \& Storen, 2000) followed by how working from home is not as effective as working in an office environment due to the lack of supervision and less support for such an environment (Rovi, 1997). The next one is the difficulty to concentrate since workers do not have a proper workroom and sufficient working space (Kelly, 1988).

We can see that these challenges mostly occur due to the lack of environment and situation that drives people's attempt to find a healthy work and life balance from working inside the bedroom (Oktra, 2020). Balancing working and resting are needed as it is hard to limit the boundaries between work and rest. It will be more difficult to balance work and personal life if workers do not get adequate or well-balanced rest (Hochschild, 1989). Therefore, balancing 
working and resting will impact the wellbeing, performance, and functioning of society (Grady et al., 2008). It will also reduce the impact of depression and exhaustion (Wegner et al., 2020). For example, the presence of windows affects computational tasks or it can be said that tasks which require focus are more motivated with the presence of windows (Stone 1998). This statement is supported by another statement that when the sunlight penetrates from the side and back of the worker, it will increase their relaxation (Boubekri, Hull, \& Boyer, 1991). The position of windows should also be considered. When it faces the west side, the window should be kept in minimal size and well shaded from the glare and when it faces the north side, the room can experience heat gain in the summer. However, thanks to the orientation of the window, it can be easily shaded to cool the house (Sustainable Energy Authority Victoria, 2002). The placement of door and furniture also impact the spaciousness and comfort (Castell, 2014). It is preferred to put the door at the corner to avoid interfering with other furniture and access (Kapple, W.H, 1992). The placement of furniture also needs some clearance space where it provides an area around the objects to allow the user in doing their activities comfortably (Kapple, W.H, 1992).

According to Gruman, lighting is one of the aspects that people do not consider in their work environment (Gruman, 2020). The room lighting intensity required for working is 350lux-500 lux (German industrial standard DIN 5035) and 120-200 lux (IESNA Lighting Handbook 9th edition, 2000) for resting. As for the color temperature, a high-color one can improve concentration, work performance, and alertness, other than waking up the occupant to start the day earlier. However, in terms of comfort, it can increase fatigue, irritability, and eye discomfort. Lower color temperature delivers a less stimulating effect, tends to be calmer, and avoids eye strain (Guide to Human Centric Lighting (HCL) for Design and Implementation, 2018). Light contrast also affects comfort while minimum contrast eases the eye's exertion, reducing eye strain, and boosting comfort (IESNA Lighting Handbook 9th edition, 2000). Meanwhile, if there is any significant contrast, it can trigger an eye sore since the eye has to readapt to the differences (DIN EN 12464-1 Light and lighting - Lighting of workplaces, Part 1: Indoor workplaces). Temperature also has a huge impact on the user comfort while working (Singh, 2018). The best quality to rest is at $24^{\circ} \mathrm{C}-26^{\circ} \mathrm{C}$ with the upper limit of $28^{\circ} \mathrm{C}$ (Minhee, 2010). Warmer or colder temperatures can affect rest negatively (Strøm-Tejsen, 2016). The temperature for working is around $21^{\circ} \mathrm{C}-25^{\circ} \mathrm{C}$ where the worker can perform most work at $20^{\circ} \mathrm{C}$ but feel uncomfortably cold. The temperature above $25^{\circ} \mathrm{C}$ will decrease performance by $2 \%$ for each degree and the performance is steady between the range of $21^{\circ} \mathrm{C}-25^{\circ} \mathrm{C}$ (Seppänen, 2003). The temperature is related to the humidity as well. Humid temperature indicates a combination of dry temperature and humidity (Lippsmeier, 1994).

We can see the quantitative measure of a comfortable room condition for working and resting in Figure 1.1. The $x$-axis shows the temperature while the $y$ axis indicates the light intensity range. The ideal working environment is shown by the combination of $21^{\circ} \mathrm{C}-25{ }^{\circ} \mathrm{C}$ in temperature and $350-500$ lux light intensity. Meanwhile, the resting ideal condition is $24^{\circ} \mathrm{C}$ $26^{\circ} \mathrm{C}$ in temperature and $120-200$ lux light intensity. The quadrant tries to see the ideal condition for both activities where the room temperature meets at $24^{\circ} \mathrm{C}-25^{\circ} \mathrm{C}$ and shows different requirements for the light intensity. The balance of color temperature for both activities is the warm white color and the source of light is dependent on the room organization. The variables of room organization, lighting, and room temperature will impact the comfort of the user if they fall behind or surpass the balance between the good working and resting space. 


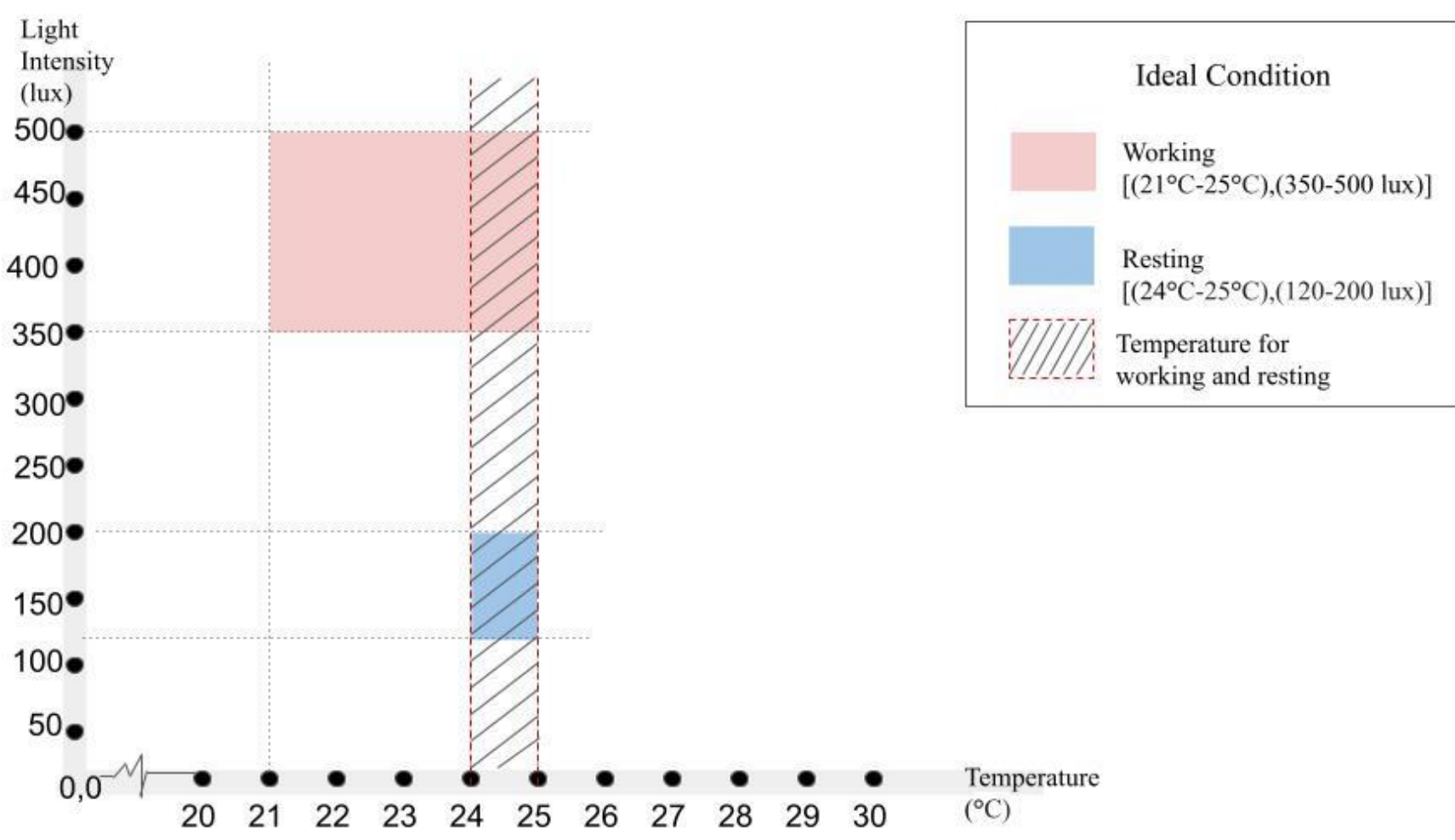

Figure 1.1. Quadrant of Light Intensity and Thermal Comfort for Working and Resting (Personal Documentation, 2021)

The need to have one room to do two different activities during the pandemic requires the balance of room organization, lighting, and room temperature which affect the user's comfort. The importance of these aspects inside the working and resting environment raises the question of what is the comfortable room condition for working and resting? The question leads to the purpose of writing this undergraduate thesis to determine the comfortable room condition in terms of the room organization, lighting, and room temperature for working and resting.

\section{Methods}

\subsection{Literature review}

This study is derived from a literature review on theories of room organization, lighting, and temperature especially those related to working activity and bedroom area. The writing consists of two study cases observation to see the application of the theories.

\section{2 Case Studies}

The case studies used two bedrooms of 25 and 26 years old workers. The data of the rooms and users was obtained through observation, filling in forms and interviews.

\section{3 Observation}

The observation was done by measuring the illuminance $75 \mathrm{~cm}$ from the ground on each spot based on SNI (SNI 16-7062-2014) by using the Light Meter application used in a smartphone and the Good Sleep application used for the color temperature.

\section{4 Interviews}

The interview was done by asking similar questions and handing a form to fill by both users. The result of the interviews was then analysed through the theories of room organization, 
lighting, and temperature. Finally, a conclusion was constructed in the last part of the thesis, based on the theories and actual data obtained from the study cases.

\section{Result and Discussion}

\subsection{Result}

Study case 1

The room surface area is $260 \mathrm{~cm} \times 470 \mathrm{~cm}$ and the orientation of the bedroom's windows is in a westward direction. The bed is placed by the window to allow more sunlight into the room in the morning. The computer table is placed in such a way that avoids direct fronting towards the window that will result in backlight and glare. The table faces the wall and the wood material of the table reduces the light since they have low reflectance.

The bedroom is installed with 2 lamps which are located above the bed and the computer table. The light used in this bedroom has a color of cool white, it is adequate for both working and resting. The white-colored ceiling helps to reflect the light.

The window has a width of $220 \mathrm{~cm}$ and a height of $120 \mathrm{~cm}$. The window frames are aluminium with black dark color. The windows are using clear glass with no glass film to reduce the sun glare. The window curtains are of contrast color compared to the window frames and wall. The curtains are in light red and of polyester material. The door to the bedroom is using wood material of light brown color. The door size is $90 \mathrm{~cm} \times 200 \mathrm{~cm}$ and uses wood frames. The silver-colored handle of the door is made of stainless-steel material. The door opens to the inside of the bedroom and it does not provide any natural light or airflow from the other side of the room.
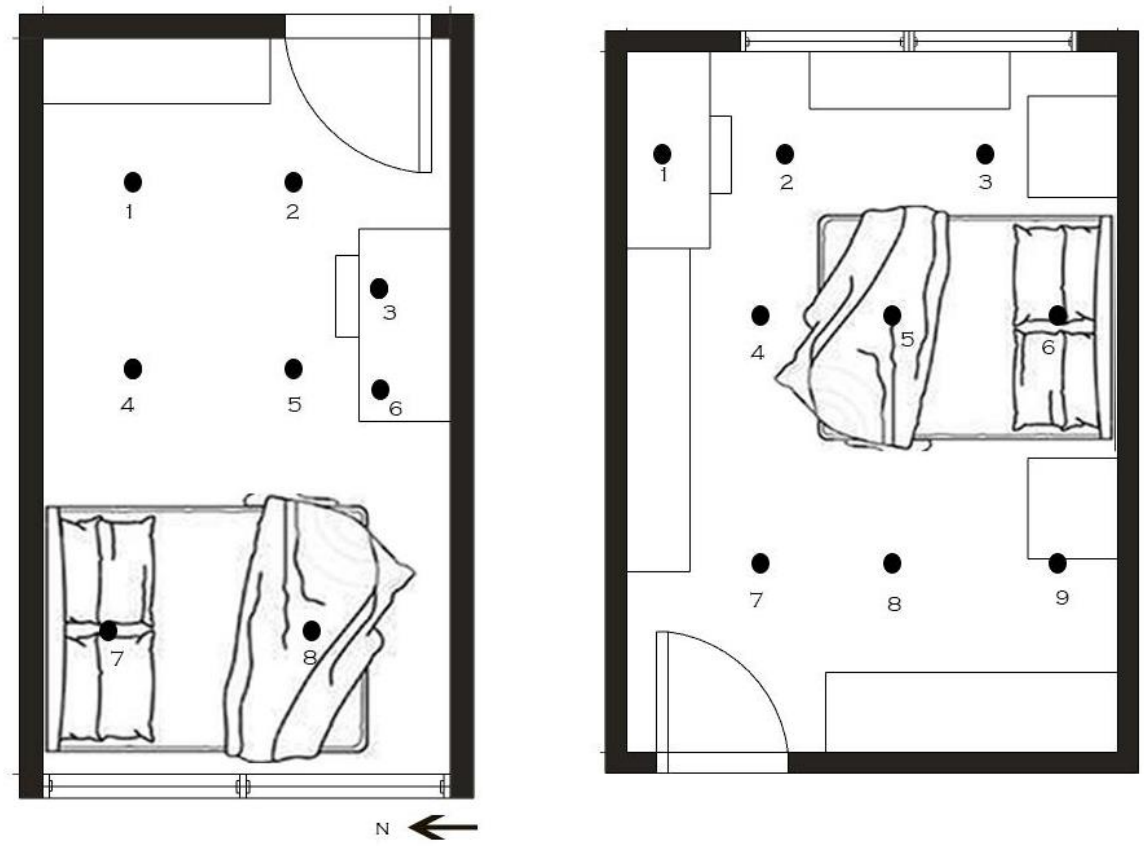

Figure 3.2. Point of Lighting Measurement (Study Case 1 (Left) and Study Case 2 (Right)) (Personal Documentation, 2020)

The lighting inside the room comes from two sources, namely natural and artificial sources. However, since the windows are westward-facing, the glare of sunlight is intense at noon. The 
user tried to reduce the glare by using a curtain. From the table, we can see that the room does not use natural light from 3:00 pm onwards since the user wants to reduce the glare (Table 3.1). The light bulbs used are cool white-colored LEDs. The measuring of the illuminance will be performed in 8 points as shown by Figure 3.2. The illuminance and temperature will be measured every one hour when the user spends most of the hour inside the room (Study case 1 timeline can be seen in Figure 3.3). The result of the measurement and source of lights used by study case 1 can be seen in Table 3.1.

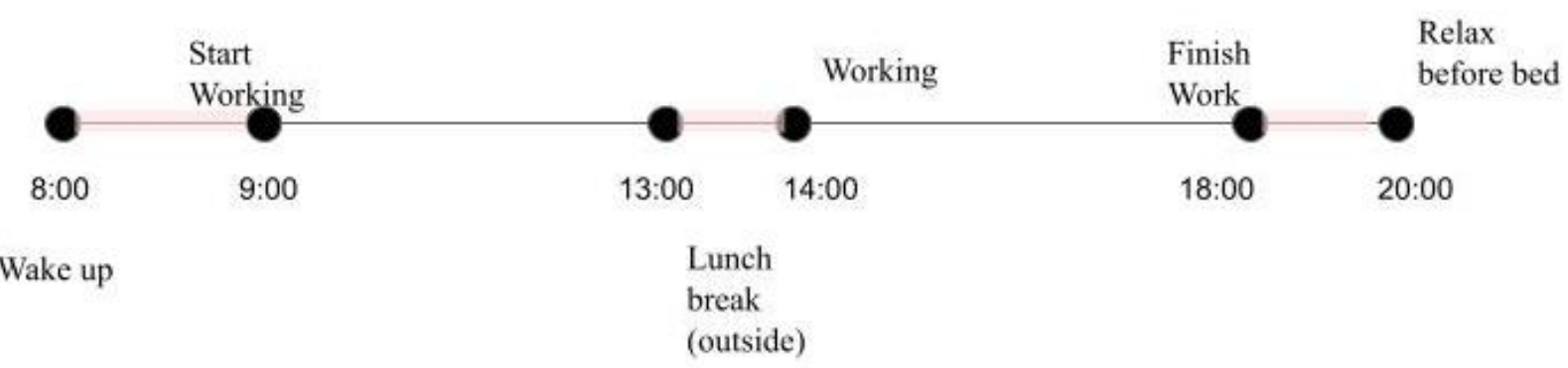

Figure 3.3 Study Case 1 Timeline (Personal Documentation, 2020)

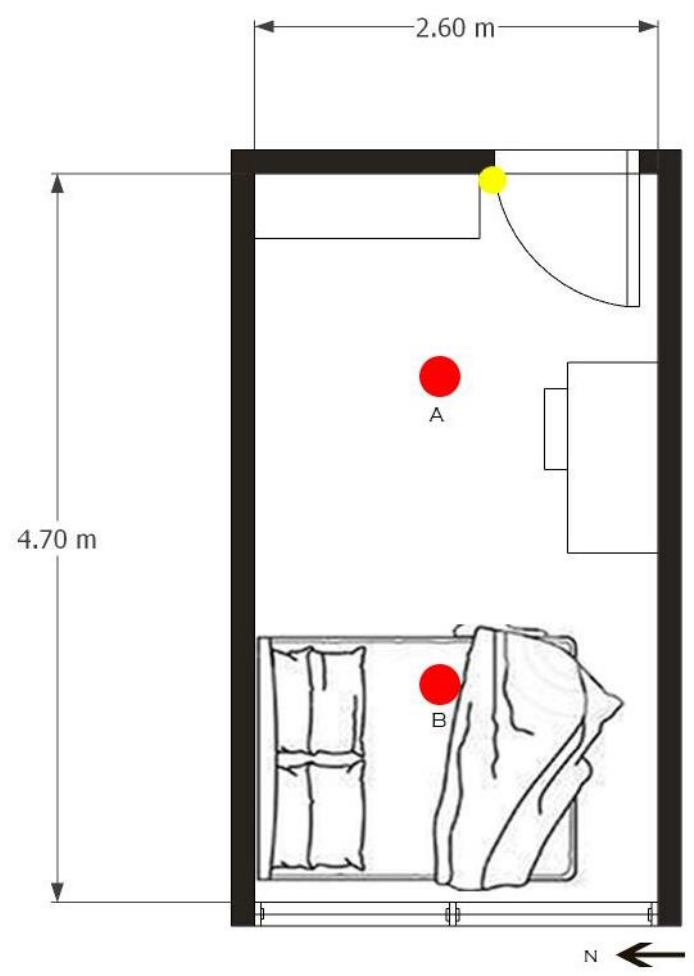

GENERAL LIGHTING

GENERAL LIGHTING SWITCH

Figure 3.4 Study case 1 Lighting Arrangement. (Personal Documentation, 2020) 
Table 3.1. Study Case 1 Illuminance and Temperature Measurement (Personal Documentation, 2020)

\begin{tabular}{|c|c|c|c|c|c|c|c|c|c|c|}
\hline \multirow[t]{2}{*}{ Time } & \multicolumn{8}{|c|}{ Measurement Point } & \multirow[t]{2}{*}{ Temperature $(\mathrm{C})$} & \multirow[t]{2}{*}{ Type of Lighting } \\
\hline & 1 & 2 & 3 & 4 & 5 & 6 & 7 & 8 & & \\
\hline 8:00 & 120 & 126 & 132 & 144 & 138 & 129 & 290 & 286 & 23 & 3 Natural \\
\hline 9:00 & 190 & 255 & 225 & 240 & 260 & 225 & 312 & 310 & 24 & Natural \\
\hline $10: 00$ & 234 & 250 & 210 & 245 & 265 & 219 & 300 & 315 & 28 & 3 Natural+Downlights A\&B \\
\hline $11: 00$ & 264 & 275 & 250 & 288 & 296 & 256 & 325 & 295 & 28 & Natural+Downlights A\&B \\
\hline $12: 00$ & 260 & 256 & 245 & 268 & 268 & 250 & 310 & 280 & 25 & Natural+Downlights A\&B \\
\hline $13: 00$ & 290 & 290 & 285 & 295 & 295 & 287 & 355 & 320 & 24 & Natural+Downlights A\&B \\
\hline $14: 00$ & 320 & 320 & 226 & 350 & 334 & 250 & 379 & 340 & 25 & Natural+Downlights A\&B \\
\hline $15: 00$ & 145 & 160 & 155 & 163 & 160 & 155 & 165 & 150 & 28 & Downlights A\&B \\
\hline $16: 00$ & 132 & 164 & 159 & 170 & 165 & 159 & 170 & 155 & 28 & Downlights A\&B \\
\hline $17: 00$ & 150 & 156 & 150 & 160 & 155 & 145 & 163 & 140 & 28 & Downlights A\&B \\
\hline $18: 00$ & 150 & 155 & 142 & 160 & 153 & 142 & 155 & 138 & 25 & Downlights A\&B \\
\hline 19:00 & - & - & - & - & - & - & - & - & & \\
\hline $20: 00$ & 105 & 110 & 98 & 90 & 100 & 50 & 85 & 60 & 23 & downlights $\mathrm{A}$ \\
\hline
\end{tabular}

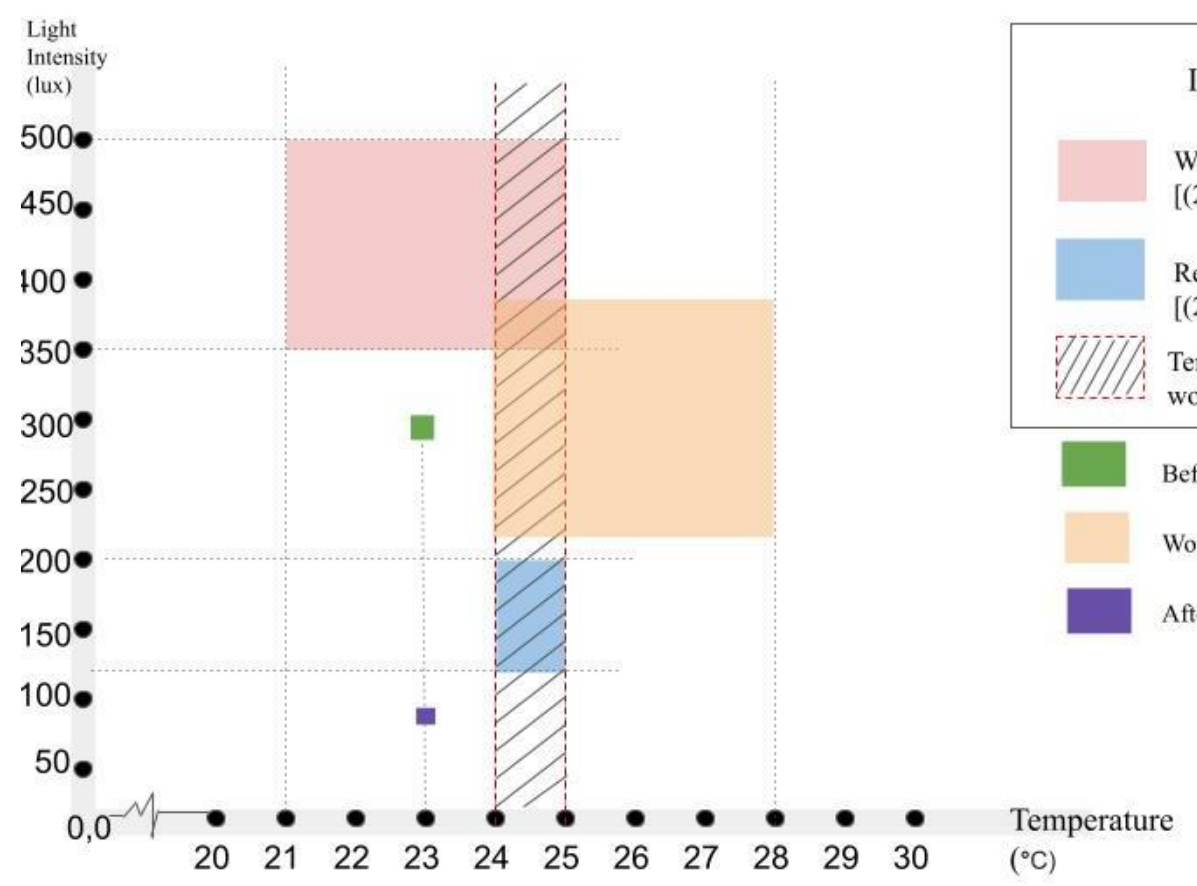

Ideal Condition

Working

$\left[\left(21^{\circ} \mathrm{C}-25^{\circ} \mathrm{C}\right),(350-500\right.$ lux $\left.)\right]$

Resting

$\left[\left(24^{\circ} \mathrm{C}-25^{\circ} \mathrm{C}\right),(120-200\right.$ lux $\left.)\right]$

Temperature for

working and resting

Before Working $\left(23^{\circ} \mathrm{C}, 290\right.$ lux $)$

Working hour $\left(24-28^{\circ} \mathrm{C}, 210-379\right.$ lux $)$

After Working $\left(23^{\circ} \mathrm{C}, 85\right.$ lux $)$

Study case 1

Figure 3.5. Quadrant of Light Intensity and Thermal Comfort for Working and Resting Study Case 1

(Personal Documentation, 2020) 
Figure 3.5. shows the condition of study case 1 room before working is at the temperature of $23^{\circ} \mathrm{C}$ and 290 lux, which is not the ideal condition to work or rest. The condition at the working hour of the user meets the requirement of the most ideal condition. The room condition after working $\left(23^{\circ} \mathrm{C}, 85 \mathrm{lux}\right)$ does not fulfil the ideal requirement for resting activities yet.

\section{Study case 2}

The room's surface area is $350 \mathrm{~cm} \times 500 \mathrm{~cm}$ and the bedroom's windows are northward facing. The bed is placed in such a way that ensures natural light without significant glare since it is facing the north side. The area of the working desk almost reached the requirement of 350 lux in the afternoon. Some areas of the room also fulfil the illuminance requirement at certain hours as can be seen in table 3.2. The working desk is equipped with indirect lighting and the placement of the computer table avoids direct fronting towards the window that will result in backlight and glare. The table overlooks the wall and the wood material of the table reduces the light since they have low reflectance. The bedroom is installed with general and additional lighting such as spotlights and indirect lights (Figure 3.6).
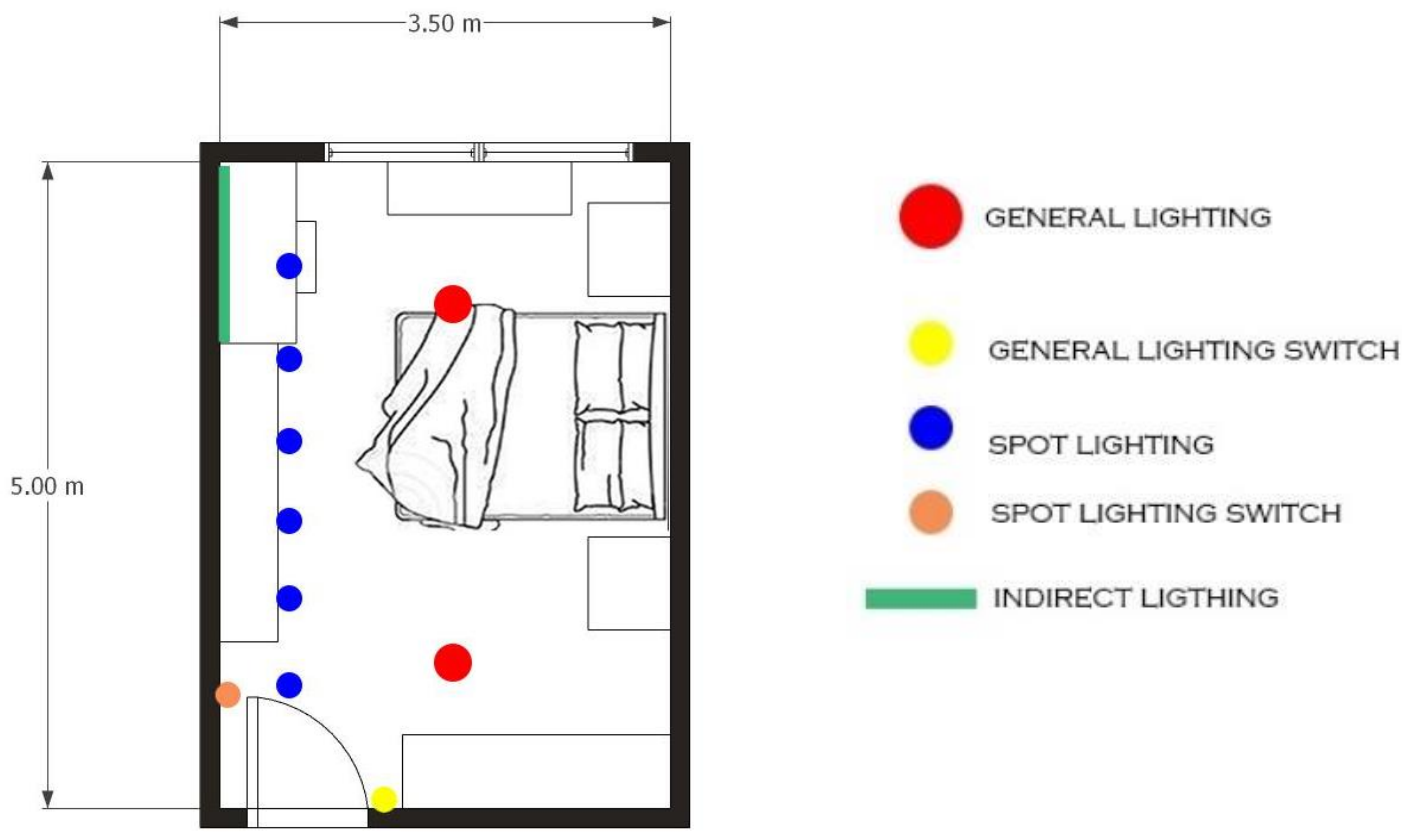

Figure 3.6. Study Case 2 Lighting Arrangement. (Personal Documentation, 2020)

The black-colored window frames are made of aluminium and use clear glass. Blinds are used on the windows instead of glass film to reduce the sun glare. The color of the plastic blind is white. The door size is $90 \mathrm{~cm}$ wide with a height of $210 \mathrm{~cm}$. The material of the door is wood of dark color with a silver-colored door handle made of stainless steel. The door opens to the inside of the room and it does not contribute any natural light from the other side of the room.

The measuring of the illuminance will be performed in 9 points as can be seen in Figure 3.2. The illuminance and temperature will be measured every one hour when the user spends most of the hour inside the room (Study case 2 timelines can be seen in Figure 3.7). The result of the measurement can be seen in Table 3.2. 


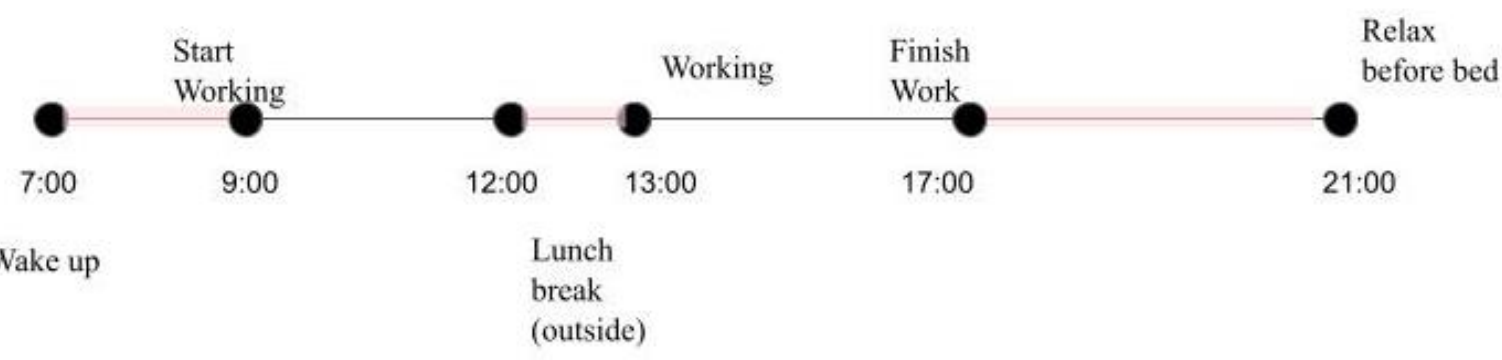

Figure 3.7. Study Case 2 Timeline. (Personal Documentation, 2020)

Table 3.2 Study case 2 Illuminance and Temperature Measurement. (Personal Documentation, 2020)

\begin{tabular}{|c|c|c|c|c|c|c|c|c|c|c|c|}
\hline \multirow[t]{2}{*}{ Time } & \multicolumn{9}{|c|}{ Measurement Point } & \multirow[t]{2}{*}{\begin{tabular}{|l} 
Tempera- \\
ture (C)
\end{tabular}} & \multirow[t]{2}{*}{ Types of lighting } \\
\hline & 1 & 2 & 3 & 4 & 5 & 6 & 7 & 8 & 9 & & \\
\hline 7:00 & 110 & 175 & 145 & 133 & 210 & 170 & 135 & 110 & 115 & 19 & Natural+spotlight \\
\hline 8:00 & - & - & & - & - & - & - & - & - & & \\
\hline 9:00 & 265 & 240 & 240 & 265 & 265 & 245 & 255 & 270 & 270 & 25 & natural+downlight $(C, D)+$ desk lamp \\
\hline 10:00 & 190 & 150 & 145 & 185 & 185 & 160 & 180 & 196 & 196 & 25 & natural+downlight $(C, D)+$ desk lamp \\
\hline $11: 00$ & 230 & 218 & 200 & 230 & 230 & 210 & 230 & 250 & 250 & 26 & natural+downlight $(C, D)+$ desk lamp \\
\hline $12: 00$ & 365 & 360 & 360 & 355 & 355 & 334 & 345 & 360 & 360 & 21 & natural+downlight $(C, D)+$ desk lamp \\
\hline 13:00 & 344 & 330 & 310 & 320 & 320 & 310 & 310 & 345 & 345 & 21 & natural+downlight(C,D)+desk lamp \\
\hline 14:00 & 350 & 365 & 350 & 350 & 350 & 345 & 346 & 375 & 375 & 20 & natural+downlight $(\mathrm{C}, \mathrm{D})+$ desk lamp \\
\hline 15:00 & 312 & 325 & 310 & 310 & 310 & 310 & 312 & 300 & 300 & 25 & natural+downlight(C,D)+desk lamp \\
\hline $16: 00$ & 310 & 310 & 317 & 310 & 310 & 300 & 310 & 320 & 320 & 25 & natural+downlight $(C, D)+$ desk lamp \\
\hline $17: 00$ & 310 & 315 & 315 & 315 & 315 & 300 & 300 & 325 & 325 & 22 & natural+downlight $(C, D)+$ desk lamp \\
\hline 18:00 & - & - & - & - & - & - & - & - & - & - & \\
\hline 19:00 & - & - & - & - & - & - & - & - & - & - & \\
\hline $20: 00$ & - & - & - & - & - & - & - & - & - & - & \\
\hline $21: 00$ & & & & & 105 & 55 & & & & 22 & spotlight \\
\hline
\end{tabular}


Figure 3.8. shows the condition of study case 2 room before working hour which is not an ideal condition for working nor resting. The condition at the working hour is ideal and meets the requirement most of the time. However, its condition after working hours is not ideal for working nor resting.

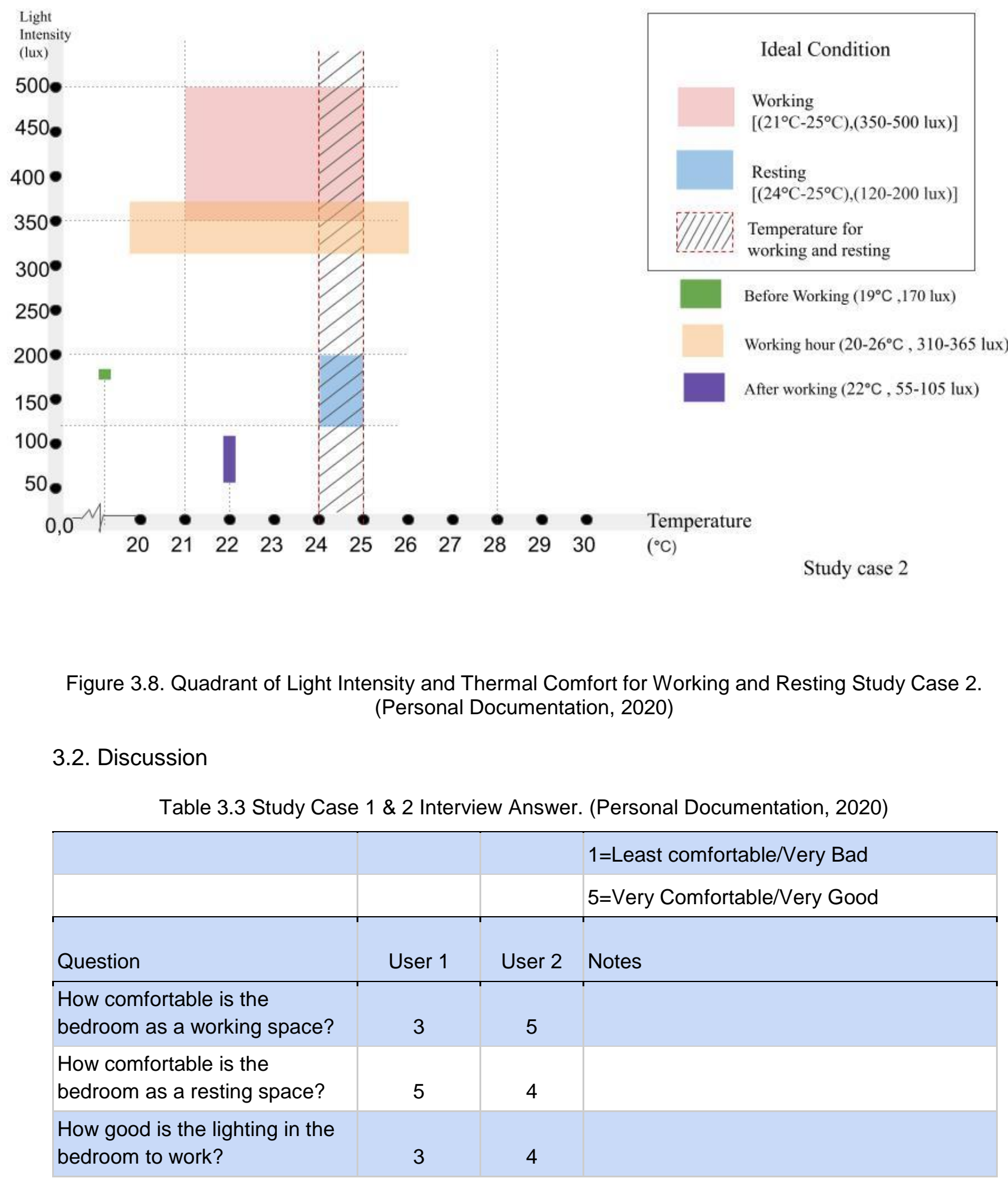




\begin{tabular}{|l|l|l|l|}
\hline $\begin{array}{l}\text { How good is the lighting in the } \\
\text { bedroom to rest? }\end{array}$ & 4 & 5 & \\
$\begin{array}{l}\text { How good is the temperature in } \\
\text { the bedroom to work? }\end{array}$ & 5 & 4 & \\
\hline $\begin{array}{l}\text { How good is the temperature in } \\
\text { the bedroom to rest? }\end{array}$ & 4 & 3 & \\
\hline $\begin{array}{l}\text { Do you have any difficulty while } \\
\text { working in your bedroom? }\end{array}$ & Yes & No & $\begin{array}{l}\text { User 1: High temperature in the afternoon } \\
\text { and easily sore eyes }\end{array}$ \\
\hline $\begin{array}{l}\text { Do you have any difficulty while } \\
\text { resting in your bedroom? }\end{array}$ & Yes & Yes & $\begin{array}{l}\text { User 1: Glare when resting in the afternoon } \\
\text { User } 2: \text { The room is stuffy without air }\end{array}$ \\
\hline
\end{tabular}

For the lighting, both study cases rely on natural and artificial lights. The difference lies in the quantity and types of luminaires, where the first case has fewer artificial light sources compared to the second case. The first bedroom has two general lights on the ceiling and relies more on the natural light. The second case has two general lights, six spotlights that hang above the shelf, and indirect light on the computer desk aiming to the wall and above the wardrobe.

Study case 1 user wakes up with 290 lux around his bed area that only comes from the natural light. The position of the bed allows the light to illuminate the bed and help in waking up the user (Guide to Human Centric Lighting (HCL) for Design and Implementation, 2018). On a scale of 1 to 5 , the user gave the lighting comfort inside his bedroom a score of 3 for working. The user works around the working desk. The measuring points of the illuminance around the working area are points 2, 3, 5, and 6 (Figure 3.2). The range of the illuminance increases until it reaches the highest number of 379 lux at point 7 (Table 3.1). He stated that his eyes tend to be sore while working. The low intensity of light and low reflectance of material behind the screen might be one of the root causes of this condition. Another reason is the color temperature emitted by the artificial, cool white-colored light. The room has a range of color temperature from $4700 \mathrm{~K}-5110 \mathrm{~K}$. Cool white color tends to have a less relaxing effect on the user compared to the warm white color. (Guide to Human Centric Lighting (HCL) for Design and Implementation, 2018)

Study case 2 user wakes up with 170-210 lux around his bed area due to the use of the spotlights and natural light (Table 3.2). On a scale of 1 to 5 , the user gave the lighting comfort inside his bedroom a score of 5 for working. The user works around the working desk area and the measuring points of the illuminance around the working area are points 1, 2, and 4 (Figure 3.2). The range of the illuminance increases until it reaches the highest number of 365 lux at point 2 at 2 pm (Table 3.2). He is comfortable with the lighting around his working area. The observation result showed that his working desk is equipped with indirect lighting directed to the plane behind his computer screen. The minimum contrast and even brightness between the screen and the wall behind have eased the eyes burden, reducing eye strain and boosting comforts (IESNA Lighting Handbook 9th edition, 2000). Another reason is the color temperature emitted by the warm, white-colored artificial light that tends to be calmer, avoiding eye strain, even though it does not increase the concentration (Guide to Human Centric Lighting (HCL) for Design and Implementation, 2018). The room has a range of color temperatures from $3000 \mathrm{~K}-3300 \mathrm{~K}$. According to table 3.2, the room's highest illuminance is achieved from 2 to $3 \mathrm{pm}$ with a range of 345 lux - 375 lux. On a scale of 1 to 5 , the user gave 
the lighting comfort inside his bedroom a score of 4 for resting. The user reduces the illuminance around the bed area where he rests, by using spotlights as the source of light. The spotlights mainly expose the cupboard area which is located on the opposite side of the bed. After 9 pm, the illuminances around the bed area are 55 lux and 105 lux (points 5 and 6) (Table 3.2). Overall, during the working hours, the illuminance meets the standard of 350 lux and the spread of brightness inside the bedroom is good that the user's eyes do not have to readapt to the differences (DIN EN 12464-1 Light and lighting - Lighting of workplaces, Part 1: Indoor workplaces). Even though he feels comfortable during work hours, it is not the case with resting. The lighting illuminance is under the standard of 120 lux. The main problem may be caused by another factor such as temperature.

The advantage of the first study case comes from the amount of sunlight that entered the room as the windows are bigger and it faces westward. However, consequently, this causes disadvantages due to the glare produced at noon. The second case has a smaller window facing northward which ensures sunlight throughout the daytime (Sustainable Energy Authority Victoria, 2002). Warm white-colored light is recommended both for working and resting as it will less likely to increase fatigue and eye discomfort along with less stimulating effect to ensure a good night sleep (Guide to Human Centric Lighting (HCL) for Design and Implementation, 2018; Knez, 2001; Mills and Tomkins, 2007). This theory is proven by the study cases: study case 1 experienced eye fatigue while study case 2 does not suffer any significant problem with the lighting. In terms of temperature, the study case 1's room tends to become warmer as the windows are facing westward. The user tends to keep the temperature range between $23^{\circ} \mathrm{C}$ to $25^{\circ} \mathrm{C}$. There is some note from the user that the temperature inside the room tends to be higher at noon, causing the user to use air conditioning to lower it. Another factor that affects the temperature is the material used inside the bedroom. The homogenous marble tile helps to make the room cooler. Another aspect such as airflow is not measured in the observation since there are no openings that will allow the airflow from outside. The user usually does not open the windows with the consideration that it will make the bedroom warmer.

In study case 2 , the user does not feel comfortable when the temperature is above the standard $25^{\circ} \mathrm{C}$ and tends to keep the temperature range between $20^{\circ} \mathrm{C}$ to $25^{\circ} \mathrm{C}$. On a scale of 1 to 5 , the user gave the room temperature comfort a score of 4 for working. However, this level drops when he rests when the room will become stuffy once the air conditioner is turned off. On a scale of 1 to 5 , the user gave the comfort level a score of 3 for resting. Another aspect such as airflow is not measured in the observation since there are no openings that will allow the airflow from outside. The user usually does not open the windows with the consideration that it will make the bedroom warmer. Considering Indonesian climate character as a tropical country, a cooling capability is needed when the outside temperature is hotter than the preferred temperature. Therefore, both cases have air conditioning installed to help in achieving the optimal condition for working and resting. Both study cases keep the room temperature at the range of $20^{\circ} \mathrm{C}-26^{\circ} \mathrm{C}$ where it mostly meets the requirement of $21^{\circ} \mathrm{C}-25^{\circ} \mathrm{C}$ (Seppänen, 2003).

\section{Conclusion}

The changes caused by pandemics require workers to bring their work home. This issue causes many people to struggle in finding a suitable and comfortable space to do their work at home. Some people do not have adequate additional space to do their work. To work inside the house, in this case, the bedroom, we need to know the requirements of the space especially the room organization, lighting, and room temperature to maintain our comfort. The variables of room organization will affect lighting and room temperature which affect the user's comforts. The level of lighting that suits the working and resting activity differs among the age groups, gender, and the types of activity (IESNA Lighting Handbook, 2000). It is significantly 
determined by the intensity, spread of brightness, and color temperature (Ideas for Good Home Lighting, 2009; Morita, Tokura. 1998). The suitable lighting for working is 350 to 500 lux while 120 lux (IESNA Lighting Handbook 9th edition, 2000) is required to get a good rest. The appropriate intensity of the light will give the best clarity that in turn will improve the comfort level. The good spread of brightness will help the eyes by minimizing the eye adjustment needed, which will make the eyes less likely to be fatigued and more focused (Ideas for Good Home Lighting, 2009).

The suitable temperature for the application of working and resting activity is the one that can hold or produce the ideal temperature of $21^{\circ} \mathrm{C}-25^{\circ} \mathrm{C}$ for working and $24^{\circ} \mathrm{C}-26^{\circ} \mathrm{C}$ for resting (Seppänen, 2003; Minhee, 2010). The users of both rooms unconsciously turn the air conditioner installed inside the room to keep the temperature between $23^{\circ} \mathrm{C}-25^{\circ} \mathrm{C}$, to keep them more comfortable inside.

In conclusion, the room organization, lighting, and room temperature affect the user physically and psychologically and this eventually the user's comfort. To increase their comfort level while having a good rest, the user needs to adjust the variables of lighting, room temperature, and room organization to achieve the optimum comfort level. The room organization affects the lighting, temperature, and comfort itself, as it will increase the relaxation when the sunlight penetrates from the side and behind them. The position of the window affects the source of light and heat gain. The placement of the objects inside the room also requires clearance space to provide space around the objects that will allow the user to perform their activities comfortably. In terms of lighting, the suitable color temperature to gain balance for both purposes is a warm white with different intensity requirements for each activity: 350 - 500 lux for working and 120 - 200 lux for resting. It can be resolved by having one adjustable source of lighting or two different lighting sources. For temperature, the optimum temperature to gain balance for both purposes is $24^{\circ} \mathrm{C}-25^{\circ} \mathrm{C}$. This undergraduate thesis also compares the literature to the study cases, and the result is that both study cases do not fulfil the balance of the variables to achieve optimum comfort level. For further research, observations towards subjects inside these conditions should be done to see whether the balance of these variables can create optimum room conditions for working and resting activities.

\section{References}

Boubekri, M., Hull, R. B.\& Boyer, L. L. (1991). Impact of window size and sunlight penetration on office workers' mood and satisfaction: A novel way of assessing sunlight. Environment and Behavior, 23, 474-493

Castell,C. (2014). The Effect of Furnishing on Perceived Spatial Dimensions and Spaciousness of Interior Space

DIN 5035 - ARTIFICIAL LIGHTING; RECOMMENDATIONS FOR WORK PLACES INDOORS AND OUTDOORS. (1990). German Institute for Standardisation (Deutsches Institut für Normung).

Establishing a New Daily Routine During the COVID-19 Pandemic. (2020, May 04). Retrieved December 15, 2020, from https://www.elcaminohealth.org/stayhealthy/blog/establishing-new-daily-routine-during-covid-19

Garmin (2020). The Impact of the Global Pandemic on Human Activity: Part III - Retrieved 2 December 2020, from https://www.garmin.com/en-US/blog/fitness/the-impact-of-theglobal-pandemic-on-human-activity-part-iii/

Guide to Human Centric Lighting (HCL) for Design and Implementation. Frankfurt am Main: Licht.de.)

Goh, K. K., Lu, M., \& Jou, S. (2020). Impact of COVID -19 pandemic: Social distancing and the vulnerability to domestic violence. Psychiatry and Clinical Neurosciences, 74(11), 612-613. 
Grady, G. (2008). Work-life balance: Policies \& initiatives in Irish organisations, a best practice management guide. Cork: Oak Tree Press.

Gruman, G. (2020, September 24). How to set up a work-from-home 'office' for the long term. Retrieved December 15, 2020, from https://www.computerworld.com/article/3545478/how-to-set-up-a-work-from-homeoffice-for-the-long-term.html

Oktra (2020). How to Work from Home During the COVID-19 Pandemic. Retrieved December 15, 2020, from https://www.oktra.co.uk/insights/how-to-work-from-home-creatingworkspace-during-the-covid-19-pandemic/

Hochschild, A. (1989). The Second Shift. New York: Avon Books.

Kapple, W.H.(1992). Bedroom Planning Standards: College of Fine and Applied ArtsUniversity of Illinois, Vol 12, No 4

Kelly, M. M. (1988). The work-at-home revolution. The Futurist (November-December), 2832.

Knez, I. (2001). Effects of colour of light on non-visual psychological processes, Journal of Environmental Psychology, 21(2), 201-208

Lippsmeier,G. (1994). Tropical Building. 2nd ed.. Syahmir Nasution, translator. Jakarta: Erlangga.

KOMPAS. (2020). Jokowi Instruksikan Bekerja dari Rumah, Ini Arti Work From Home Halaman all - Kompas.com. Retrieved 30 November 2020, from https://www.kompas.com/tren/read/2020/03/16/195035165/jokowi-instruksikanbekerja-dari-rumah-ini-arti-work-from-home?page=all

Mills, P. R. and Tomkins, S. C. (2007). The effect of high correlated colour temperature office lighting on employee well-being and work performance, Journal of Circadian Rhythms, $5(2)$

Minhee,K \& Chungyoon,C. \& Jinkyu,H. (2010). A Study on Bedroom Environment and Sleep Quality in Korea

Morita T., Tokura H., 1998. The influence of different wavelengths of light on human biological rhythms. Applied Human Science 17(3): 91-96.

Rea, M. S., \& Illuminating Engineering Society of North America. (2000). The IESNA lighting handbook: Reference \& application. New York, NY: Illuminating Engineering Society of North America.

Rovi, S. (1997), "BUT ARE THEY EXPLOITED?: INDUSTRIAL HOME WORKERS IN THE 1990 NEW JERSEY CENSUS", International Journal of Sociology and Social Policy, Vol. 17 No. 3/4, pp. 63-101

Scripps Health. (Ed.). (2020, July 06). Create an Ergonomic Workspace at Home. Retrieved January 08, 2021, from https://www.scripps.org/news_items/7000-creating-anergonomic-workspace-at-home-during-covid-19

Seppänen,O \& Fisk,W.J \& Lei,Q.H.(2003). Effect of Temperature on Task Performance in Office Environment

Singh, N. (2018, September 04). Temperature Impacts Workplace Productivity Too. Retrieved December 15, 2020, from https://www.entrepreneur.com/article/319479

SNI. (2001). SNI Pencahayaan,SNI 03-65765-2001

Stone, N. J. (1998). Windows and environmental cues on performance and mood. Environment and Behavior, 30, (3), 306-321.

Strøm-Tejsen, P., Zukowska, D., Wargocki, P. and Wyon, D.P. (2016), The effects of bedroom air quality on sleep and next-day performance. Indoor Air, 26: 679-686. https://doi.org/10.1111/ina.12254

Sustainable Energy Authority Victoria (2002). Window Placement and Sizing, Siting and Solar Access.

Wegner, M., Amatriain-Fernández, S., Kaulitzky, A., Murillo-Rodriguez,E., Machado, S., \& Budde, H. (2020). Systematic review of meta-analyses: Exercise effects on depression in children and adolescents. Frontiers in Psychiatry, 11,81. 